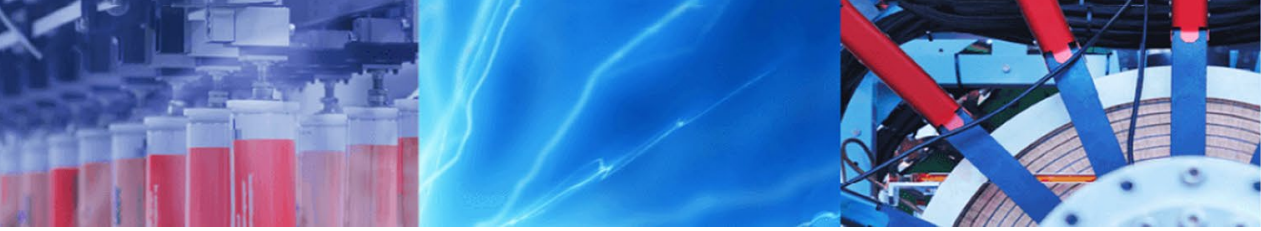

Research Article

\title{
Biosorption of heavy metal polluted soil using bacteria and fungi isolated from soil
}

\author{
Oluwafemi Adebayo Oyewole ${ }^{1}$. Stella Suanu Leh-Togi Zobeashia ${ }^{2} \cdot$ Emmanuel Olalekan Oladoja $^{1}$. \\ Ramat Onyeneoyiza Raji ${ }^{1}$. Esther Eguye Odiniya ${ }^{1}$. Abdullmajid Makun Musa ${ }^{1}$
}

() Springer Nature Switzerland AG 2019, corrected publication 2019

\begin{abstract}
Heavy metals polluted soils have turned out to be a common environmental problem across the globe due to their toxic effects and accumulation through the food chain. Heavy metals have lethal effects on all forms of life. For instance, plants grown on heavy metal polluted soil show a reduction in growth and yields. A surge in anthropogenic activities and industrial operations has substantially increased the level of heavy metal pollution and release into the environment; hence, there is need to remediate these heavy metal pollutants. Biosorption is an efficient, economical, ecofriendly and convenient techniques of remediating heavy metal polluted soils. It is a widely accepted method that utilizes biomaterials such as natural biomass as biosorbents. The current study was based on the biosorption of copper, chromium, cadmium and nickel polluted soil using bacteria and fungi isolated from soil. Bacterial species isolated were Pseudomonas, Bacillus, Micrococcus, Escherichia, Streptococcus, Enterobacter and Staphylococcus while fungi isolated were Aspergillus niger, Penicillium notatum and Aspergillus flavus. The isolated bacteria were screened for potential to biosorb copper and chromium likewise fungi for cadmium and nickel. Biosorption rate was determined using atomic absorption spectrophotometry. Five milliliters each of a-day-old culture of the screened bacteria and fungi was inoculated into $45 \mathrm{ml}$ of nutrient broth (bacteria) and potato dextrose broth (fungi) having concentrations of 5, 10, 15 and $20 \mathrm{ppm}$, respectively, of copper, chromium, cadmium and nickel. The conical flasks were incubated at a temperature of $37^{\circ} \mathrm{C}$ and $28{ }^{\circ} \mathrm{C} \pm 2$ for bacteria and fungi, respectively, for a period of 35 days of inoculation. For the bacterial isolates, the highest biosorption rates of chromium (89.67\%) and copper (90.89\%) by Pseudomonas aeruginosa were observed at $20 \mathrm{ppm}$ on day 21 and 15 ppm on day 14 , respectively, while for the fungi isolates, P. notatum showed highest biosorption rate for cadmium at $10 \mathrm{ppm}$ with $77.67 \%$. Aspergillus niger showed highest biosorption rate for nickel with $81.07 \%$ after 28 days of incubation. The results of this study revealed the ability of Pseudomonas aeruginosa to biosorb copper and chromium and also A. niger and $P$. notatum to biosorb cadmium and nickel from the environment and can be developed for the biosorption of soils polluted with copper, chromium, cadmium and nickel.
\end{abstract}

Keywords Biosorption $\cdot$ Cadmium $\cdot$ Copper $\cdot$ Nickel $\cdot$ Chromium $\cdot$ Bacteria $\cdot$ Fungi

\section{Introduction}

Heavy metals are natural elements with atomic number greater than 20 , characterized by a relatively high density (at least $5 \mathrm{~g} \mathrm{~cm}^{-3}$ ), and are toxic even at low concentrations [1-3]. They are characteristically existing components found in changing variation in the environments and are part of human daily activities, they are also found in important structures and in a range of other artificial mixes [4]. The activities of human have greatly impacted on some heavy metal biochemical cycles and equalization of which

$\triangle$ Oluwafemi Adebayo Oyewole, oyewolefemi@gmail.com | 'Department of Microbiology, Federal University of Technology, Minna, Nigeria. ${ }^{2}$ National Biotechnology Development Agency, Lugbe, Abuja, Nigeria.

SN Applied Sciences (2019) 1:857 | https://doi.org/10.1007/s42452-019-0879-4

Received: 11 April 2019 / Accepted: 2 July 2019 / Published online: 15 July 2019 
a great number of heavy metals have found its use in various items such as cars and batteries [5].

Heavy metals are generated from both anthropogenic and natural sources and are eventually discharged into the environment $[6,7]$. The main natural discharge of heavy metals is during volcanic eruptions and weathering of metal-bearing rocks [2]. The discharge of heavy metals through various man-made activities, for example excessive application of chemical fertilizers, wood burning, coal combustion, vehicle exhaust, mining, smelting and incineration [2], has caused a wide spread disruption of the normal biogeochemical cycles of metals causing a larger accumulation of heavy metals in the environment, especially the soil [6-8]. The major heavy metals of concern include lead, cadmium, arsenic, mercury, copper and chromium because of their toxic impact on human health; for instance, environmental exposure to high concentrations of heavy metals has been linked with various cancers and kidney issues [9]. Heavy metals have also greatly affected soil microorganisms and plants growth and development [10]. The presence of heavy metals in the environment has been a source of concern over the past few decades due to their persistence, potential harm and toxicological hazards [2]. Besides the fact that they are non-biodegradable, they may also undergo microbial or chemical transformation $[8,9,11,12]$. Recently, Hasani et al. [13] and Nath et al. [3] reported that heavy metal polluted environments activate co-selection process and cause a decrease in microbial tolerance to antibiotics due to their ability to co-regulate genes responsible for antibiotic resistance.

The soil is a reservoir for some essential trace elements such as zinc and copper, which are necessary for the growth of plants and animals, but external influence can increase their concentration and consequently reduce the overall soil fertility and agricultural productivity. Therefore at soil concentration above normal level, if permitted to accumulate in the food chain, heavy metals such as lead and cadmium can have adverse effects on human and animal health [14]. There is also the risk of leaching of heavy metals, and this may contaminate underground water and in turn affect human health, especially those that consume underground water through boreholes and well water [1]. The increase in industrialization and urbanization offers ascend to heavy metal pollution of the environment, which might have resulted from the discharge of effluents containing metals such as lead, cadmium, chromium, nickel and mercury $[6,7,15]$.

According to Thompson and Darwish [14], heavy metals are of genuine environmental concern because of their potential toxicity, reactivity and soil mobility. The emissions of these metal pollutants have become a severe threat to mankind. The routes of exposure of human to heavy metals include inhalation, dermal absorption and ingestion $[2,16]$. In order to alleviate the environmental impacts of heavy metal, several efforts are currently being adopted. Such methods include thermal, chelating, precipitation, adsorption, ion exchange, membrane technologies and biosorption strategies. Biosorption has several advantages over other conventional methods of heavy metal remediation because of its accessibility and efficiency [15]. One important economic aspect of biosorption technology is that the biomass used for decontamination of heavy metal pollutants is natural, easily available and affordable, and also it provides a better performance compared to conventional methods of decontamination $[17,18]$. Thus, there is the need to apply affordable metal remediation technology like biological method so as to reduce the toxic effect of these heavy metals in the environment.

Biosorption is a biological remediation technology that involves the removal of metal species from a solution by inexpensive biomaterials, and it has been reported that most biological materials can be useful as biosorbents for heavy metals sequestration and can be a vital passive procedure in organisms, but the exceptions are mobile alkali metal cations like $\mathrm{Na}^{+}$and $\mathrm{K}^{+}$[19]. Most biosorbent materials have good biosorption capacities toward all types of metal ions, so many affordable and easily available biosorbents used for the elimination of heavy metals in the environment are mainly derived from bacteria, fungi, algae, plants and some polysaccharide materials. Many researches involving biosorption of heavy metals from the environment have been carried out in vitro and in vivo [19]. Karthik et al. [20] and Karthik et al. [21] reported the biosorption and bioaccumulation of high chromium by Cellulosimicrobium funkei AR8 and AR6, respectively, under batch conditions. Dhanarani et al. [15] reported the biosorption of aluminum by Bacillus safensis. Live and dead biomass of Aspergillus niger have been used to biosorb fluoride in aqueous solution under batch and continuous condition [22].

The materials used for biosorption include a solid stage biomaterial (sorbent) and a solvent stage containing disintegrated species like metal particles to be sorbed (sorbate). Similar to each sorption procedure, binding of sorbate species to biosorbent proceeds until it reaches a balance between the sorbate species in fluid and solid stages. Biosorbents contain some atomic groups that have tendency to sorbates, for example, metal ions. This innovation utilizes different sorts of biomass to expel heavy metals from contaminated environment $[19,23]$.

Biosorbents of biological origin particularly various microorganisms have received growing interest for the removal of heavy metal and recovery owing to their greater performance $[7,24]$. Although biosorption is influenced by many factors such as $\mathrm{pH}$, temperature and contact time $[6,25]$, the use of microorganisms as biosorbent 
materials offers a selective removal of heavy metals under varied physicochemical properties, adsorption and desorption and another advantage of microorganisms is their high surface-to-volume ratio [7, 17]. Several microorganisms have been used for biosorption, examples include Bacillus cereus used in Cd [26] and Cu [6] removal, Cellulosimicrobium funkei AR6 and Cellulosimicrobium funkei AR8 used in biosorption of $\mathrm{Cr}[20,21]$, Bacillus safensis used to biosorb aluminum [15], Aspergillus niger used for fluoride biosorption [22], and Pugazhendhi et al. [6] reported lead biosorption using Ralstonia solanacearum. Therefore, this study is aimed at determining the biosorption rate of cadmium, nickel, chromium and copper by fungi and bacteria isolated from soil.

\section{Materials and methods}

\subsection{Collection of soil samples}

Soil used was collected from botanical garden of Biological Science Department, Federal University of Technology, Minna, Nigeria, and transported in a polythene bag to the microbiology laboratory for further analysis.

\subsection{Media preparation}

For fungi isolation, potato dextrose agar was prepared according to manufacturer's instruction and was autoclaved at $121{ }^{\circ} \mathrm{C}$ for $15 \mathrm{~min}$ and was allowed to come to room temperature, and then, chloramphenicol would be added to the media to inhibit bacteria growth while for bacteria isolation, nutrient agar and nutrient broth were prepared according to manufacturer's specification and were autoclaved at $121^{\circ} \mathrm{C}$ for $15 \mathrm{~min}$ and then aseptically transferred into petri dishes and conical flask, respectively, and allowed to solidify.

\subsection{Isolation of microorganism}

The microorganisms were isolated by pour plate technique on potato dextrose agar (PDA) for fungi and nutrient agar (NA) for the enumeration of aerobic heterotrophic bacteria. Prior to isolation, the soil samples were serially diluted from $10^{-1}$ to $10^{-10}$. The $1 \mathrm{ml}$ of the diluents from $10^{-4}$ and $10^{-6}$ was aseptically inoculated into media using pour plate method and incubated at ambient temperature for $24-72 \mathrm{~h}$ for fungi and $37^{\circ} \mathrm{C}$ for $24 \mathrm{~h}$ for bacteria. Each colony that appeared on the plate was considered as one colony-forming unit (cfu). The bacterial and fungal colonies were subcultured repeatedly on potato dextrose agar and nutrient agar plates, respectively, to obtain a pure isolate. The pure isolates were stored in agar slants for further characterization and identification [27].

\subsection{Identification of fungi isolates}

After obtaining a pure culture of the fungal isolates, macroscopic and microscopic examination of pure isolates was carried out. The characterization was based on the colonial and morphological characteristics. The fungal colony was observed, and microscopic examination was carried out by placing a drop of distilled water and a portion of the fungi on a slide, covered with a cover slip and observed on a microscope with $10 \times$ objective and then $40 \times$ objective. Important details such as vegetative structure of hypha, septa, etc., as well as reproductive structures including the type and shape of spore were noted for identification of each isolate [28].

\subsection{Characterization and identification of bacterial isolates}

The bacterial isolates were characterized by colonial morphology and biochemical characteristics such as Gram stain, spore stain, motility, catalase, oxidase, coagulase, indole, methyl-red test (MR-VP), urease, Simmons citrate test and triple sugar iron agar using methods described by Cheesbrough [27] and Bergey's manual of determinative bacteriology [29].

\subsection{Preparation of metal solutions}

The stock solution of cadmium sulfate and nickel sulfate was prepared by dissolving $3.73 \mathrm{~g}$ and $4.48 \mathrm{~g}$, respectively, in $1 \mathrm{~L}$ of distilled water. Also, the stock solution of potassium dichromate $\left(\mathrm{K}_{2} \mathrm{Cr}_{2} \mathrm{O}_{7}\right)$ and copper sulfate $\left(\mathrm{CuSO}_{4}\right)$ was prepared by dissolving $2.5 \mathrm{~g}$ and $5.8 \mathrm{~g}$, respectively, in $1 \mathrm{~L}$ of distilled water. The stock solutions were agitated for $15 \mathrm{~min}$ and then allowed to stand for a period of $24 \mathrm{~h}$ in other to obtain a complete dissolution of salt. The initial cadmium, nickel, copper and chromium concentrations were measured using atomic absorption spectrophotometry (UV-Vis 752, UK). The $\mathrm{pH}$ of the solution was also adjusted to $\mathrm{pH} 7$ using sodium hydroxide $(\mathrm{NaOH})$ and hydrochloric acid [18].

\subsection{Screening of microorganisms for biosorption of heavy metals}

The isolates were randomly screened for their abilities to biosorb the heavy metals. The $5 \mathrm{ml}$ of fungi culture was inoculated into $45 \mathrm{ml}$ of potato dextrose broth having $5 \mathrm{ppm}$ of $\mathrm{Cd}$ and Ni separately. Similarly, $5 \mathrm{ml}$ of a-dayold bacterial culture was inoculated into $45 \mathrm{ml}$ of nutrient 
broth having $5 \mathrm{ppm}$ of $\mathrm{Cu}$ and $\mathrm{Cr}$ separately. The metal $\mathrm{pH}$ solution was adjusted to the $\mathrm{pH}$ value of 7 before the different isolates were added to the solution. The conical flasks containing PDA were incubated at $28 \pm 2{ }^{\circ} \mathrm{C}$ while those containing nutrient broth were incubated at a temperature of $37^{\circ} \mathrm{C}$. Each conical flask was withdrawn after 7 days of inoculation; centrifugation was done at $1792 \mathrm{G}$ for $25 \mathrm{~min}$. The supernatant was digested using nitric acid of $4 \mathrm{ml}$ for every metal solution sample. The concentration of metal was determined by absorption spectrophotometry (UV-Vis 752, UK) [17]. The percentage of biosorption was determined by Beer Lambart's law: (\%) biosorption $=$ initial metal concentration - final metal concentration*100/initial metal concentration.

\subsection{Biosorption of heavy metal}

Five milliliters ( $5 \mathrm{ml}$ ) broth of fungi culture was inoculated into $45 \mathrm{ml}$ of potato dextrose broth having different concentration (5,10,15 and $20 \mathrm{ppm})$ of $\mathrm{Cd}$ and $\mathrm{Ni}$ separately. Five milliliters $(5 \mathrm{ml})$ of a-day-old bacterial culture was inoculated into $45 \mathrm{ml}$ of nutrient broth having different concentrations of $\mathrm{Cu}$ and $\mathrm{Cr}$ separately $(5 \mathrm{ppm}, 10 \mathrm{ppm}$, $15 \mathrm{ppm}, 20 \mathrm{ppm}$ ). The metal $\mathrm{pH}$ solution was adjusted to the $\mathrm{pH}$ value of 7 before the different isolates were added to the solution. The conical flasks containing PDA were incubated at $28 \pm 2{ }^{\circ} \mathrm{C}$ while those containing nutrient broth were incubated at a temperature of $37^{\circ} \mathrm{C}$. Each conical flask was withdrawn at specific time intervals of 7, 14, 21 and 28 days of inoculation, and centrifugation was done at $4000 \mathrm{rpm}$ for $25 \mathrm{~min}$. After centrifuging, the supernatant was digested in correspondence with their varying concentration using nitric acid of $4 \mathrm{ml}$ for every metal solution sample. The concentration of metal was determined by absorption spectrophotometry (UV-Vis 752 , UK) [17]. The percentage of biosorption was determined by Beer Lambart's law: (\%) biosorption = initial metal concentration - final metal concentration $* 100 /$ initial metal concentration.

\subsection{Data analysis}

Data generated from this study were subjected to statistical package for social science (SPSS 23) using one-way analysis of variance (ANOVA) and Tukey's HSD.

\section{Results}

\subsection{Microorganisms isolated from the soil samples}

Seven bacterial isolates were obtained after series of subculturing of the bacterial cultures isolated from the soil.
The bacteria were identified as species of Bacillus, Escherichia, Micrococcus, Enterobacter, Pseudomonas, Staphylococcus and Streptococcus while the fungi isolates were identified as Aspergillus niger, Aspergillus flavus and Penicillium notatum.

\subsection{Microorganisms screened for biosorption potential}

Screening of fungi isolate for biosorption potential shows that the three fungi were capable of absorbing the heavy metals. Aspergillus niger showed a higher sorption rate of $43.69 \%$ in nickel solution, Penicillium notatum also showed a high sorption rate of $38.87 \%$ in cadmium solution while Aspergillus flavus gave a lower biosorption rate of $42.69 \%$ in cadmium and $17.0 \%$ in nickel solutions of the same concentration and at the same time intervals. There was a significant difference $(P<0.05)$ between the \% biosorption rates by each isolate (Table 1 ).

The bacterial isolates were subjected to screening under similar metal concentration and environmental conditions to check for their potential to carry out the biosorption process. After subjecting the isolated bacteria to screening, all the bacteria isolated were capable of biosorbing chromium and copper but at different rates. Pseudomonas aeruginosa showed the highest biosorption rate and was observed to be more effective compared to the other isolated bacteria. There was a significant difference $(P<0.05)$ between the \% biosorption rates by each isolate (Table 2). Based on these results, Aspergillus niger was used to biosorb nickel, Penicillium notatum was used to biosorb cadmium while $P$. aeruginosa was utilized in the biosorption of copper and chromium.

\subsection{Biosorption of cadmium and nickel by fungi isolates}

The biosorption rates for Penicillium notatum and Aspergillus niger are shown in Figs. 1 and 2, respectively. The highest biosorption by Penicillium notatum was observed

Table 1 Fungi isolates screened for biosorption potential

\begin{tabular}{lcc}
\hline Fungal isolates & Cadmium (\%) & Nickel (\%) \\
\hline Aspergillus niger & $19.18^{\mathrm{b}}$ & $\mathbf{4 3 . 6 9}^{\mathrm{a}}$ \\
Aspergillus flavus & $17.00^{\mathrm{c}}$ & $42.69^{\mathrm{b}}$ \\
Penicillium notatum & $\mathbf{3 8 . 8 1}^{\mathrm{a}}$ & $20.00^{\mathrm{c}}$ \\
Control & $1.84^{\mathrm{d}}$ & $1.65^{\mathrm{d}}$ \\
\hline
\end{tabular}

Mean of values in the same column with different superscripts differs significantly $(P<0.05)$ from each other

Bold indicates the highest values obtained during the screening for the ability of the microorganisms to utlise the heavy metals. That informed their selection for the biosorption experiments 
Table 2 Bacteria isolates screened for biosorption potential

\begin{tabular}{lcc}
\hline Bacterial isolates & Chromium (\%) & Copper (\%) \\
\hline Bacillus lentus & $38.03^{\mathrm{b}}$ & $36.33^{\mathrm{b}}$ \\
Escherichia coli & $4.47^{\mathrm{g}}$ & $8.63^{\mathrm{f}}$ \\
Micrococcus roseus & $36.56^{\mathrm{c}}$ & $20.33^{\mathrm{c}}$ \\
Enterobacter aerogenes & $22.09^{\mathrm{d}}$ & $14.87^{\mathrm{e}}$ \\
Pseudomonas aeruginosa & $\mathbf{4 5 . 5 9 ^ { \mathrm { a } }}$ & $\mathbf{4 2 . 6 9 ^ { \mathrm { a } }}$ \\
Staphylococcus aureus & $19.94^{\mathrm{e}}$ & $17.28^{\mathrm{d}}$ \\
Streptococcus species & $13.87^{\mathrm{f}}$ & $4.86^{\mathrm{g}}$ \\
Control & $0.41^{\mathrm{h}}$ & $0.65^{\mathrm{h}}$ \\
\hline
\end{tabular}

Mean of values in the same column with different superscripts differs significantly $(P<0.05)$ from each other

Bold indicates the highest values obtained during the screening for the ability of the microorganisms to utlise the heavy metals. That informed their selection for the biosorption experiments

at 20 ppm with $77.67 \%$ on the 28th day, and the lowest was observed at $10 \mathrm{ppm}$ on the 7 th day (Fig. 1). At day 7 of 5 ppm, 10 ppm, 15 ppm and 20 ppm, lower biosorption rates were observed by Aspergillus niger with $43.69 \%$, $26.04 \%, 42.17 \%$ and $56.98 \%$ respectively while at the end of 28 th day higher sorption rate of $75.46 \%, 72.79 \%, 80.11 \%$ and $81.07 \%$ were recorded for 5 ppm, 10 ppm, 15 ppm and 20 ppm, respectively (Fig. 2).

\subsection{Biosorption of chromium and copper by bacterial isolates}

The bacterial isolates were subjected to screening under similar metal concentration and environmental conditions to check for their potential to carry out the biosorption process. After subjecting the isolated bacteria to screening, all the bacteria isolated are capable of biosorbing heavy metals but at different rates. Pseudomonas aeruginosa showed highest biosorption rate and was observed to be more effective compared to the other isolated bacteria and the control. The biosorption rates generally increased, corresponding to increase in the days of
Fig. 1 Biosorption of cadmium by Penicillium notatum

Fig. 2 Biosorption of nickel by Aspergillus niger
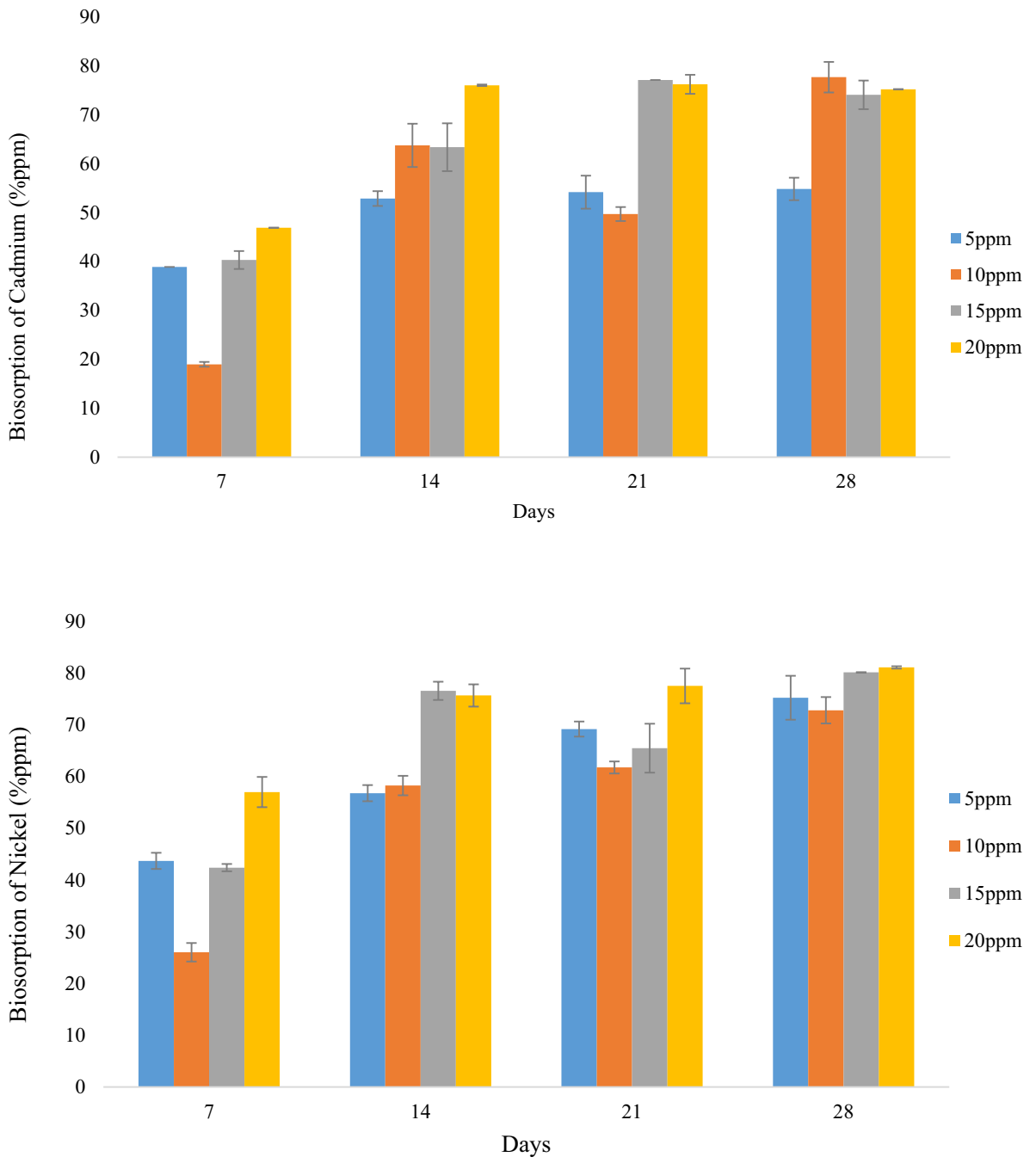
incubation. The highest rate was observed at $20 \mathrm{ppm}$ after 21 days (Fig. 3) and 15 ppm after 14 days (Fig. 4).

\section{Discussion}

The result of screening of fungi isolate for biosorption potentials revealed that of the three different species of fungi isolated, Aspergillus niger showed a significantly higher biosorption rate of $43.69 \%$ in nickel solution $(P<0.05)$ while Penicillium notatum also showed a significantly higher sorption rate of $38.87 \%$ in cadmium solution $(P<0.05)$. The ability of these isolates to take up the heavy metals may be due to some of their inherent physiological characteristics such as the cell wall. Penicillium notatum has a rigid and complex cell wall that contains polysaccharides such as chitins and glucans, and also has higher surface-to-volume ratio which help these fungi to absorb cadmium into their cell wall [30].
Penicillium notatum also releases some extracellular enzymes such as laccases and metal binding proteins that act as chelators that binds heavy metals and facilitates absorption by the cell wall. When compared to control, a high level of cadmium was taken up by Penicillium notatum in that solution. Similar findings were recorded by Leitao [31] who reported that Penicillium notatum isolated from heavily polluted streams near industrial area was able to grow and remove 100-fold higher cadmium level after 13 days of incubation by an absorption process. Also Abdulwahab [32] reported that Penicillium notatum can survive in a mineral liquid medium containing up to $400 \mu \mathrm{g} / \mathrm{ml}$ of cadmium and other metals such as zinc, aluminum and zinc.

Similarly, Aspergillus niger is a filamentous fungus that is capable of absorbing nickel from the environment. Just like Penicillium notatum, the metal binding capacity of Aspergillus niger is due to its physiological characteristics. Aspergillus niger has a complex cell wall that is made up of chitins, glucans, inorganic ions, lipids, nitrogen
Fig. 3 Biosorption of chromium by Pseudomonas aeruginosa
Fig. 4 Biosorption of copper by Pseudomonas aeruginosa
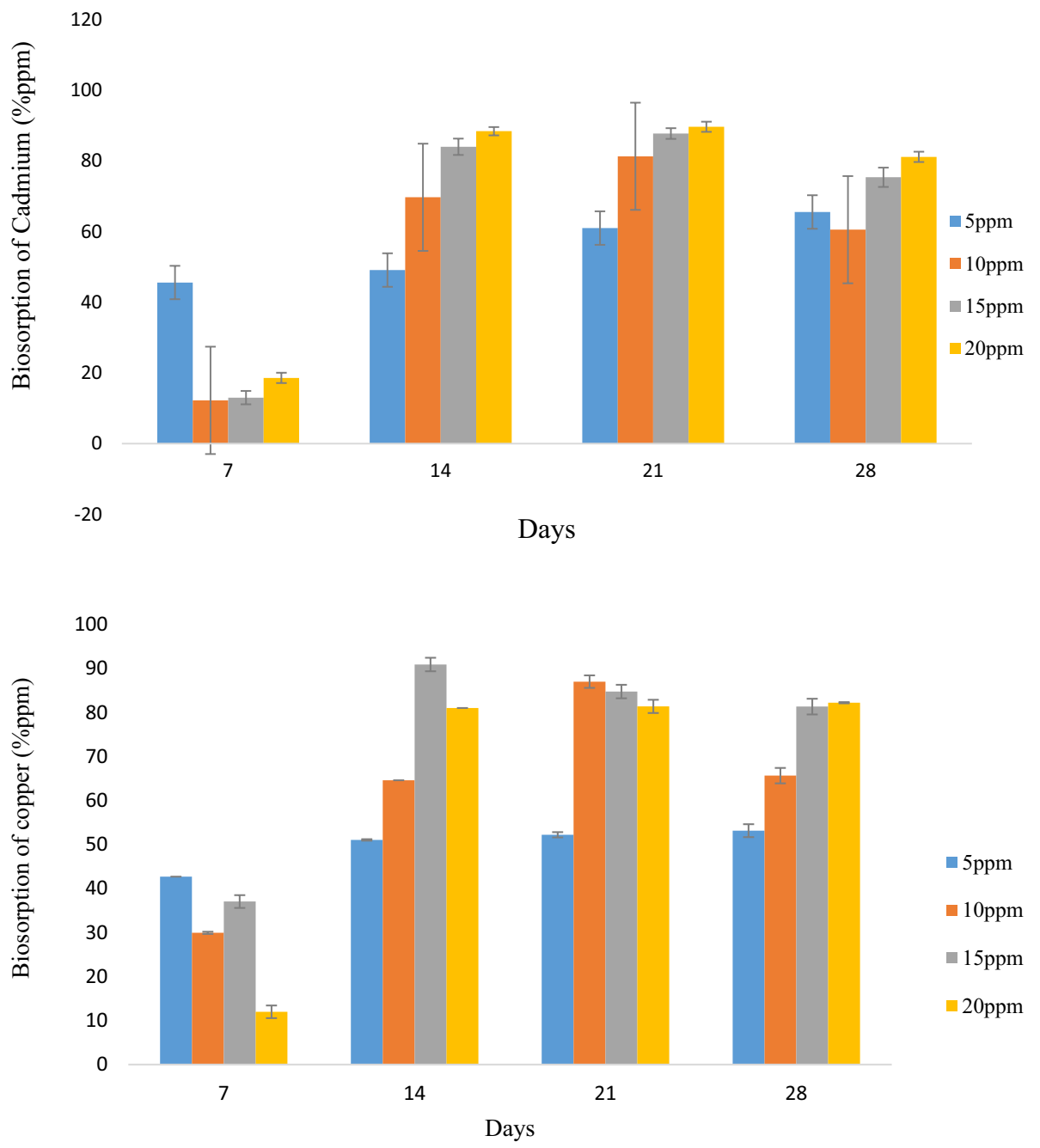
containing polysaccharide and proteins that can tolerate and detoxify nickel by active uptake [30]. Extracellular and intracellular precipitation of these features allows Aspergillus niger to absorb nickel into their cell wall [30]. Compared to control, high level of nickel was taken up by $A$. niger in that solution (Fig. 2) which shows that Aspergillus niger is capable of absorbing nickel in a solution. The highest sorption rate observed on the 21 st day at $15 \mathrm{ppm}$ and $20 \mathrm{ppm}$ and not on the 28th day may be due to the fact that cadmium is toxic to the fungal cells at higher concentration and longer period of exposure could damage the cells of these fungi, which may lead to their death and reduce the biosorption rate. This result is similar to the result obtained by labal et al. [33] who isolated Aspergillus niger and Penicilluim species from soil for biosorption, and recorded that Aspergillus niger and Penicillium species have promising biosorption capacity for nickel, chromium and cadmium in solution, but Aspergillus niger shows preference to nickel compared to Penicillium species.

The use of Pseudomonas species was studied in different concentrations of chromium $(5,10,15$ and $20 \mathrm{ppm})$ and also at different time intervals $(7,14,21$ and 28 days). The highest biosorption rate of chromium by Pseudomonas aeruginosa was observed at $20 \mathrm{ppm}$ on day 21 (Fig. 3), and the highest biosorption rate of copper by Pseudomonas aeruginosa was recorded at $15 \mathrm{ppm}$ on day 14 (Fig. 4). The ability of Pseudomonas aeruginosa to take up certain heavy metal from the environment may be due to the nature of their cell wall. The cell wall of Pseudomonas species contains lipopolysaccharides, protein and phospholipids. The lipopolysaccharide present in the cell wall contains phosphate and carboxyl groups and phospholides, which are the primary sites of metal ion binding, thereby making biosorption process possible by the microorganism. Abioye et al. [23] found that Pseudomonas aeruginosa has been accounted for as effective chromium reducer. In comparative study, on the selective binding of different metals to the cell wall of Pseudomonas species, copper had much more affinity than other heavy metals like nickel and cadmium when evaluated together [34, 35].

There was an increased biosorption rates on day 7 down to day 21 in 5, 10, 15 and 20 ppm concentration of chromium and copper. After day 21, there was a slight decline in sorption by the organism. The reason for the decline in the rate of biosorption from day 21 and 28 of chromium and copper could be as a result of the saturation of the organism-metal binding sites or could be as a result of the fact that chromium and copper at higher concentration and a longer period could cause damage to the cell of the microorganism.

\section{Conclusion}

The study was based on the biosorption of copper, chromium, cadmium and nickel polluted soil using $P$. aeruginosa, Aspergillus niger and Penicillium notatum isolated from soil. The results obtained from this study revealed that the isolates were able to biosorb various concentrations of the heavy metals and can be developed for the biosorption of soils contaminated with copper, chromium, cadmium or nickel.

\section{Compliance with ethical standards}

Conflict of interest There is no conflict of interest in the preparation of this article.

\section{References}

1. Koller M, Saleh HM (2018) Introductory chapter: introducing heavy metals, heavy metals. Hosam El-Din M. Saleh and Refaat F. Aglan, IntechOpen, https://doi.org/10.5772/intechopen.74783 . https://www.intechopen.com/books/heavy-metals/introducto ry-chapter-introducing-heavy-metals

2. Ali H, Khan E, Ilahi I (2019) Environmental chemistry and ecotoxicology of hazardous heavy metals: environmental persistence, toxicity, and bioaccumulation. J Chem 2019, 6730305. https:// doi.org/10.1155/2019/6730305

3. Nath S, Paul P, Roy R, Bhattacharjee S, Deb B (2019) Isolation and identification of metal-tolerant and antibiotic-resistant bacteria from soil samples of Cachar district of Assam, India. SN AppI Sci 1:727. https://doi.org/10.1007/s42452-019-0762-3

4. Govind A, Kumari J (2014) Understanding the terrestrial carbon cycle: an ecohydrological perspective. Int J Ecol 712537:1-18

5. Oyeleke OP, Abiodun OA, Rasaki AS, Odeyemi OE, Ajibade TB (2016) Assessment of some heavy metals in the surrounding soil of an automobile battery factory in Ibadan, Nigeria. J Environ Sci Technol 10(1):1-8

6. Pugazhendhi A, Boovaragamoorthy GM, Ranganathan K, Naushad M, Kaliannan T (2018) New insight into effective biosorption of lead from aqueous solution using Ralstonia solanacearum: characterization and mechanism studies. J Clean Prod 174:1234-1239

7. Masindi V, Muedi KL (2018) Environmental contamination by heavy metals, heavy metals. Hosam El-Din M. Saleh \& Refaat F. Aglan, IntechOpen, https://doi.org/10.5772/intechopen.76082. https://www.intechopen.com/books/heavy-metals/environmen tal-contamination-by-heavy-metals. Assessed 5 June 2019

8. Nwidi IC, Agunwamba JC (2015) Selection of biosorbents for biosorption of three heavy metals in a flow-batch reactor using removal efficiency as parameter. Nigerian J Technol 34(2):406-413

9. García R, Campos J, Cruz JA, Calderón M, Raynal E, Buitrón G (2016) Biosorption of $\mathrm{Cd}, \mathrm{Cr}, \mathrm{Mn}$, and $\mathrm{Pb}$ from aqueous solutions by Bacillus sp strains isolated from industrial waste activate sludge. Rev Espec Cienc Quím Biol 19(1):5-14

10. Sharma A, Kumar V, Handa N, Bali S, Kaur R, Khanna K, Thukral AT, Bhardwaj R (2018) Potential of endophytic bacteria in heavy metal and pesticide detoxification. In: Egamberdieva D, 
Ahmad P (eds) Plant microbiome: stress response. Microorganisms for sustainability, vol 5. Springer, Singapore. https://doi. org/10.1007/978-981-10-5514-0_14

11. Lentini P, Zanoli L, Cal M, Granata A, Dell'Aquila R (2019) Lead and heavy metals and the kidney. Critical Care Nephrology (Third Edition), pp 1324-1330. https://doi.org/10.1016/B9780-323-44942-7.00222-3

12. Das KK, Honnutagi R, Mullur L, Reddy RC, Das S, AbdulMajid SA, Biradar MS (2019) Heavy metals and low-oxygen microenvironment-its impact on liver metabolism and dietary supplementation dietary interventions in liver disease. Foods Nutr Dietary Suppl 2019:315-332. https://doi.org/10.1016/B978-0-12-81446 6-4.00026-4

13. Hasani A, Madhi M, Gholizadeh P, Mojarrad JS, Rezaee MA, Zarrini G, Kafil HS (2019) Metal nanoparticles and consequences on multi-drug resistant bacteria: reviving their role. SN Appl Sci 1:360. https://doi.org/10.1007/s42452-019-0344-4

14. Thompson LA, Darwish WS (2019) (2019) Environmental chemical contaminants in food: review of a global problem. J Toxicol 2019, 2345283. https://doi.org/10.1155/2019/2345283

15. Dhanarani $S$, Viswanathan $E$, Piruthiviraj $P$, Arivalagan $P$, Kaliannan T (2016) Comparative study on the biosorption of aluminum by free and immobilized cells of Bacillus safensis KTSMBNL 26 isolated from explosive contaminated soil. J Taiwan Inst Chem Eng 69:61-67

16. World Health Organization (WHO) (2018) Lead poisoning and health. https://www.who.int/news-room/fact-sheets/detail/ lead-poisoning-and-health. Assessed 6 June 2019

17. Munees A, Mulgeta K (2013) Recent trends in microbial biosorption of heavy metals: a review. Indian J Exp Biol 1(1):19-26

18. Abioye OP, Yusuf GB, Aransiola SA, Oyewole OA, Bala JD (2017) Biosorption of chromium and zinc by Micrococcus virians and Staphylococcus aureus isolated from soil. Int Res J Environ Sci 6(6):1-7

19. Mustapha MU, Halimoon N (2015) Microorganisms and biosorption of heavy metals in the environment: a review paper. J Microb Biochem Technol 7:253-256. https://doi. org/10.4172/1948-5948.1000219

20. Karthik C, Barathi S, Pugazhendhi A, Ramkumar VS, Thi NBD, Arulselvi PI (2017) Evaluation of $\mathrm{Cr}(\mathrm{VI})$ reduction mechanism and removal by Cellulosimicrobium funkei strain AR8, a novel haloalkaliphilic bacterium. J Hazard Mater 333:542-553

21. Karthik C, Ramkumar VS, Pugazhendhi A, Gopalakrishnan K, Arulselvi PI (2017) Biosorption and biotransformation of $\mathrm{Cr}(\mathrm{VI})$ by novel Cellulosimicrobium funkei strain AR6. J Taiwan Inst Chem Eng 70:282-290

22. Annadurai ST, Arivalagan P, Sundaram R, Mariappan R, Pudukadu A (2019) Batch and column approach on biosorption of fluoride from aqueous medium using live, dead and various pretreated Aspergillus niger(FS18) biomass. Surf Interfaces 15:60-69. https ://doi.org/10.1016/j.surfin.2019.01.013

23. Abioye OP, Oyewole OA, Oyeleke SB, Adeyemi MO, Orukotan AA (2018) Biosorption of lead, chromium and cadmium in tannery effluent using indigenous microorganisms. Braz J Biol Sci 5(9):13-24. https://doi.org/10.21472/bjbs.050903

24. Kumar R, Sharma AK, Singh P, Dhir B, Mehta D (2014) Potential of some fungal and bacterial species in bioremediation of heavy metals. J Nucl Phys Mater Sci Radiat Appl 1:213-223

25. Shanmugaprakash M, Venkatachalam S, Rajendran K, Pugazhendhi A (2018) Biosorptive removal of $\mathrm{Zn}(\mathrm{II})$ ions by Pongamiaoil cake (Pongamia pinnata) in batch and fixed-bed column studies using response surface methodology and artificial neural network. J Environ Manag 227:216-228. https://doi.org/10.1016/j. jenvman.2018.08.088

26. Arivalagan P, Singaraj D, Haridass V, Kaliannan T (2014) Removal of cadmium from aqueous solution by batch studies using Bacillus cereus. Ecol Eng 71:728-735. https://doi.org/10.1016/j.ecole ng.2014.08.005

27. Cheesbrough M (2006) District laboratory practice in tropical countries. Part 2. Cambridge University Press, Cambridge

28. Bahobil A, Bayoumi RA, Atta HM, El-Sehrawey MM (2017) Fungal biosorption for cadmium and mercury heavy metal ions isolated from some polluted localities in KSA. Int J Curr Microbiol Appl Sci 6(6):2138-2154

29. Holt JG, Krieg NR, Sneath PHA, Staley JT, Williams ST (1994) Bergy's manual of determinative bacteriology. Williams and Wilkins Publishers, Maryland

30. Chaney RL, Angle JS, Broadhurst CL, Peters CA, Tappero RV (2007) Improved understanding of hyper-accumulation yields commercial phytoextraction and phytomining technologies. J Environ Qual 36:1429-1443

31. Leitao AL (2009) Potential of Penicillium species in bioremediation of field. Int J Environ Res Publ Health 6:1393-1417

32. Abdulwahab RH (2015) Fungal biosorption and tolerance of heavy metals. J Agric Sci Technol 5:77-80

33. Iqbal A, Ansari MI, Aqil F (2006) Biosorption of nickel, chromium and cadmium by metal tolerant Aspergillus niger and Penicillium species using single and multiple metal solution. Indian J Exp Biol 44:73-76

34. Ahemad A, Malik A (2012) Bioaccumulation of heavy metals by zinc resistant bacteria isolated from agricultural soils irrigated with wastewater. Bacteriol J 2:12-21

35. Hrynkiewicz K, Złoch M, Kowalkowski T, Baum C, Niedojadło K, Buszewski B (2014) Strain-specific bioaccumulation and intracellular distribution of $\mathrm{Cd}^{2+}$ in bacteria isolated from the rhizosphere, ectomycorrhizae, and fruit bodies of ectomycorrhizal fungi. Environ Sci Pollut Res Int 22(4):3055-3067

Publisher's Note Springer Nature remains neutral with regard to jurisdictional claims in published maps and institutional affiliations. 